\title{
Assessing circularity interventions: a review of EEIOA-based studies
}

\author{
Glenn A. Aguilar-Hernandez , Carlos Pablo Sigüenza-Sanchez, Franco Donati, João F. D. Rodrigues \\ and Arnold Tukker
}

*Correspondence: g.a.aguilar@cml.leidenuniv.nl Institute of Environmental Sciences (CML), Leiden University, Leiden, The Netherlands

\begin{abstract}
Environmentally extended input-output analysis (EEIOA) can be applied to assess the economic and environmental implications of a transition towards a circular economy. In spite of the existence of several such applications, a systematic assessment of the opportunities and limitations of EEIOA to quantify the impacts of circularity strategies is currently missing. This article brings the current state of EEIOA-based studies for assessing circularity interventions up to date and is organised around four categories: residual waste management, closing supply chains, product lifetime extension, and resource efficiency. Our findings show that residual waste management can be modelled by increasing the amount of waste flows absorbed by the waste treatment sector. Closing supply chains can be modelled by adjusting input and output coefficients to reuse and recycling activities and specifying such actions in the EEIOA model if they are not explicitly presented. Product lifetime extension can be modelled by combining an adapted final demand with adjusted input coefficients in production. The impacts of resource efficiency can be modelled by lowering input coefficients for a given output. The major limitation we found was that most EEIOA studies are performed using monetary units, while circularity policies are usually defined in physical units. This problem affects all categories of circularity interventions, but is particularly relevant for residual waste management, due to the disconnect between the monetary and physical value of waste flows. For future research, we therefore suggest the incorporation of physical and hybrid tables in the assessment of circularity interventions when using EEIOA.
\end{abstract}

Keywords: Circular economy, Input-output analysis, Waste management, Recycling, Closing loops, Resource efficiency, Product lifetime extension

\section{Background}

In the early 1990s, the concept of circular economy was proposed by Pearce and Turner (1990) as a model to transform the traditional open-ended economy into an ongoing closed-loop system from a material perspective. Since then, several scholars and practitioners have adopted multiple definitions for circularity (Winans et al. 2017). After considering 114 conceptual frameworks, Kirchherr et al. (2017) define it as an economic system that substitutes product end-of-life with a set of circularity interventions.

Circularity interventions are actions or processes that preserve resources inside the economy (Lieder and Rashid 2016a; Bocken et al. 2017). Such actions are based on three principles (Ellen MacArthur Foundation 2013; Ghisellini et al. 2016): 
- Minimising waste disposal through the use of waste flows as inputs for other economic activities;

- Optimising material loops through the design of products and services that allows extending product lifetime, reuse and recycling materials at their end-of-life;

- Promoting a restorative environment through the development of renewable energy that decreases material extraction and its environmental impacts.

Implementing circularity interventions has become a prominent topic in sustainability policies (McDowall et al. 2017). For instance, the European Commission presented an action plan for the circular economy in which interventions are related to the design of long-lasting products, material closed-loops at multiple supply chain levels, resource efficiency and sustainable waste management (EC 2015). Another example is that of the Chinese circular economy initiatives of the 1990s, which seek to prolong product lifetime and to enhance resource efficiency (Geng et al. 2012, 2016). These and other governments have implemented circularity actions as mechanisms to achieve economic prosperity and environmental sustainability (Andersen 2007; Ghisellini et al. 2016; Geissdoerfer et al. 2017).

In order to maximise the economic and environmental benefits of circularity interventions, it is important to assess their cost-effectiveness. This can be done through the application of analytical methods that assess the impact of particular policies (Elia et al. 2017; Potting et al. 2017). However, there is no recognised framework for measuring how effective a country is in making a transition to circularity (EEA 2016; Linder et al. 2017). Such an approach needs to integrate indicators with a clear understanding of the circularity mechanism influencing multiple economic activities and their environmental performance (Lieder and Rashid 2016b; Pauliuk 2017).

The assessment of circularity interventions can be addressed by environmentally extended input-output analysis (EEIOA). In fact, as described further below, EEIOA has been used to evaluate the impacts of residual waste management, reusing and recycling activities, product lifetime extension, and resource efficiency (Duchin 1992; Iacovidou et al. 2017).

Assessing these interventions through EEIOA has in turn required adapting that same framework, leading to the development of new methods. For example, the study of the interdependency between production and waste generation led to the development of waste input-output models (Nakamura 1999b). In addition, the analysis of resource use and emissions at country level in relation to potential leakage on a global level (WEF 2014; Rutherford and Böhringer 2015) resulted in the development of multiregional models for assessing the impacts embodied in international trade (Peters and Hertwich 2009; Wiedmann 2009; Tukker and Dietzenbacher 2013). Finally, circularity interventions are usually implemented using financial incentives such as subsidies and taxes that need to be endogenised to account for all impacts of the policy (Ferrão et al. 2014). The theoretical integration of financial incentives in the waste input-output model was achieved by Rodrigues et al. (2016). Such adaptations of EEIOA framework have been relevant to evaluate the potential impacts of current circular implementation.

To promote the further advancement and implementation of best practices in the use of EEIOA to assess the economic and environmental implications of circularity 
interventions, it is important to critically evaluate existing studies. To the best of our knowledge, no such review has previously been compiled.

We fill this knowledge gap by offering a literature review of EEIOA-based circularity interventions and suggest opportunities for improvement. The paper proceeds as follows. Section 2 describes the data and methods used in the literature survey. Section 3 presents the actual literature review, describing how in the past circularity interventions have been addressed, organised around four categories: residual waste management, closing supply chains, product lifetime extension, and resource efficiency. Section 4 synthesises the main methodological aspects of each intervention type. Section 5 then discusses the major contributions and limitations as well as opportunities for improvement and Sect. 6 closes with some final remarks.

\section{Methods}

In order to facilitate the identification of EEIOA-based studies related to circular strategies, we organised circularity interventions based on the resource flow framework proposed by Ellen MacArthur Foundation (2013), Bocken et al. (2016), and Kirchherr et al. (2017). Given such framework, we then collected 13 keywords that are commonly used to identify circular strategies (Ghisellini et al. 2016; Bocken et al. 2017; den Hollander et al. 2017a). Table 1 shows the categories evaluated in this review as well as their definition and corresponding keywords.

We applied the keywords of Table 1 to query online databases of peer-reviewed scientific publications in English (i.e. Web of Science and Scopus) and identified 163 documents that combined 'input-output analysis' and at least one term related to circularity interventions when screening title, abstract and keywords. Afterwards we manually examined the content of the documents, restricting our analysis to 47 relevant

Table 1 Circularity intervention categories

\begin{tabular}{|c|c|c|c|}
\hline Intervention category & Description & Based on & Keywords \\
\hline $\begin{array}{l}\text { Residual waste manage- } \\
\text { ment (RWM) }\end{array}$ & $\begin{array}{l}\text { Related to post-consump- } \\
\text { tion activities where the } \\
\text { materials are disposed } \\
\text { outside the economy }\end{array}$ & $\begin{array}{l}\text { Ellen MacArthur Founda- } \\
\text { tion (2013) } \\
\text { Kirchherr et al. (2017) }\end{array}$ & $\begin{array}{l}\text { Landfill } \\
\text { Energy recovery } \\
\text { Waste treatment }\end{array}$ \\
\hline $\begin{array}{l}\text { Closing supply chains } \\
\text { (CSC) }\end{array}$ & $\begin{array}{l}\text { The re-integration of } \\
\text { materials at different } \\
\text { levels of the supply } \\
\text { chain after being used, } \\
\text { via for instance product } \\
\text { reuse, component } \\
\text { re-use, refurbishing, and } \\
\text { recycling }\end{array}$ & $\begin{array}{l}\text { Bocken et al. (2016) } \\
\text { Ellen MacArthur Founda- } \\
\text { tion (2013) } \\
\text { Kirchherr et al. (2017) }\end{array}$ & $\begin{array}{l}\text { Reuse } \\
\text { Redistribution } \\
\text { Refurbishment } \\
\text { Remanufacture } \\
\text { Recycle }\end{array}$ \\
\hline $\begin{array}{l}\text { Product lifetime extension } \\
\text { (PLE) }\end{array}$ & $\begin{array}{l}\text { Associated with slowing- } \\
\text { down the resource use } \\
\text { as a consequence of } \\
\text { extending lifetime of } \\
\text { products, via for instance } \\
\text { design for longevity and } \\
\text { improved maintenance }\end{array}$ & $\begin{array}{l}\text { Bocken et al. (2016) } \\
\text { Kirchherr et al. (2017) }\end{array}$ & $\begin{array}{l}\text { Product lifetime Extension } \\
\text { Maintenance } \\
\text { Repair }\end{array}$ \\
\hline Resource efficiency (RE) & $\begin{array}{l}\text { Processes or mecha- } \\
\text { nisms which optimise } \\
\text { resource flows by using } \\
\text { less resources per unit } \\
\text { produced }\end{array}$ & $\begin{array}{l}\text { Bocken et al. (2016) } \\
\text { Kirchherr et al. (2017) }\end{array}$ & $\begin{array}{l}\text { Resource efficiency } \\
\text { Material efficiency }\end{array}$ \\
\hline
\end{tabular}


documents. We then developed a backwards/forwards snowballing process (Wohlin 2014), identifying additional relevant literature from the citation network. In total we found 93 relevant documents.

In order to identify basic attributes of the selected publications, we collected data on the year of publication and number of citations, circularity intervention covered, and EEIOA model characteristics.

Figure 1 shows the number of articles published in each year and the number of yearly citations of all previously published papers. The figure shows that there has been a gradual increase in the number of EEIOA-based studies that assess circularity, with $60 \%$ of all relevant literature published in the past 5 years. Figure 2 shows that the majority of studies are focused on the interaction between recycling and waste treatment systems $(n[\mathrm{CSC}+\mathrm{RWM}]=35)$. Moreover, residual waste management is the most common intervention, present in 68 study cases, followed by closing supply chains $(n[C S C]=54)$, product lifetime extension $(n[\mathrm{PLE}]=17)$ and resource efficiency $(n[\mathrm{RE}]=13)$.

Table 2 presents a characterisation of the top- 10 most cited papers. Table 3 provides a technical characterisation of the type of model and/or approach used in different studies concerning the type of table, units, time and geographical scope. Most studies (88\%) use harmonised input-output tables (IOTs), use hybrid units (53\%), are focused on a specific year $(85 \%)$ and are applied to a single country $(75 \%)$. A detailed list of specific characteristics of the reviewed publication is provided in the Additional file 1.

Although there are examples of circular intervention assessments at the macro-economic level developed by governments and private institutions in the grey literature (for example, Bastein et al. 2013; Pratt and Lenaghan 2015; Rutherford and Böhringer 2015; McKinsey\&Company 2016), most of these studies apply bottom-up methods,

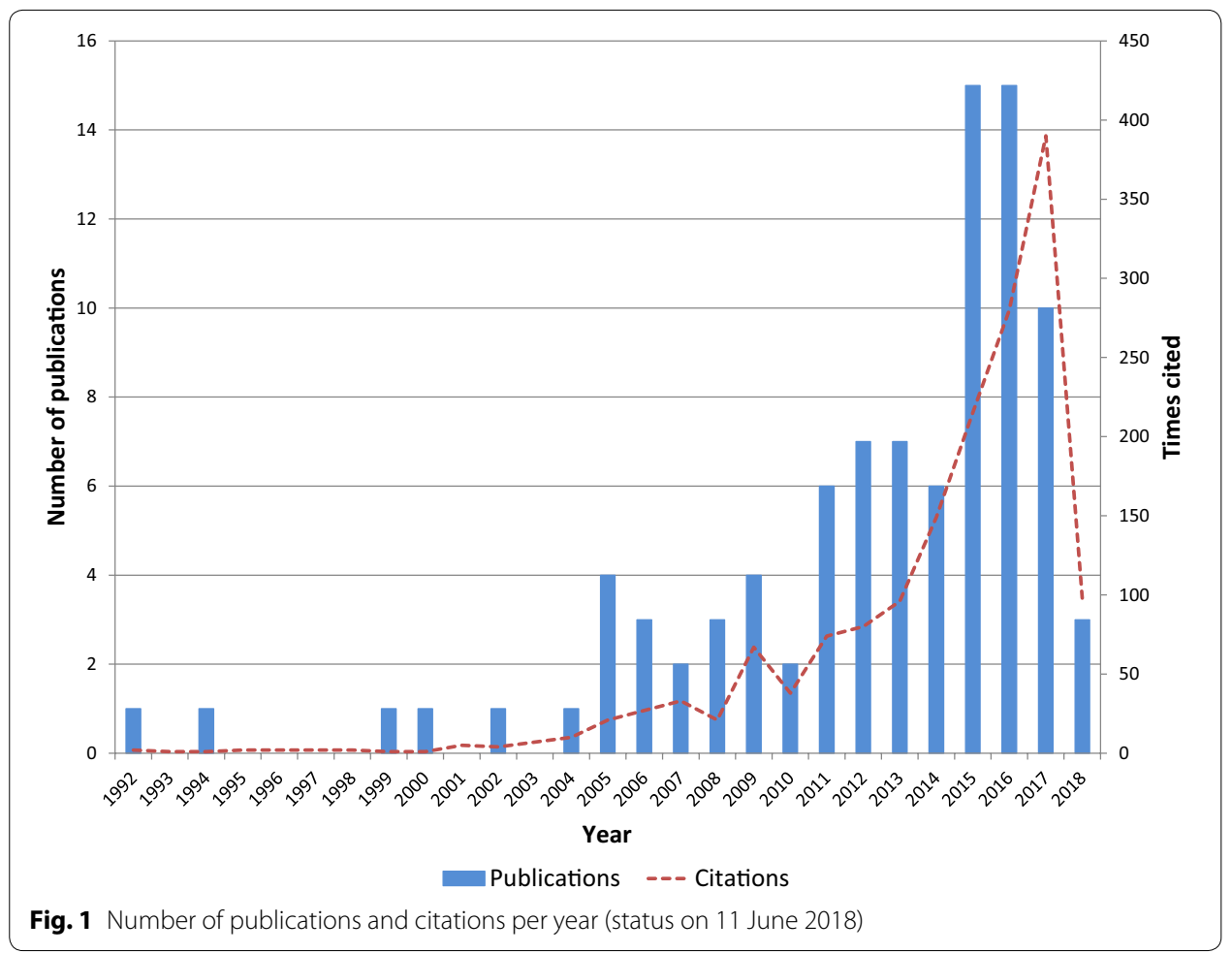




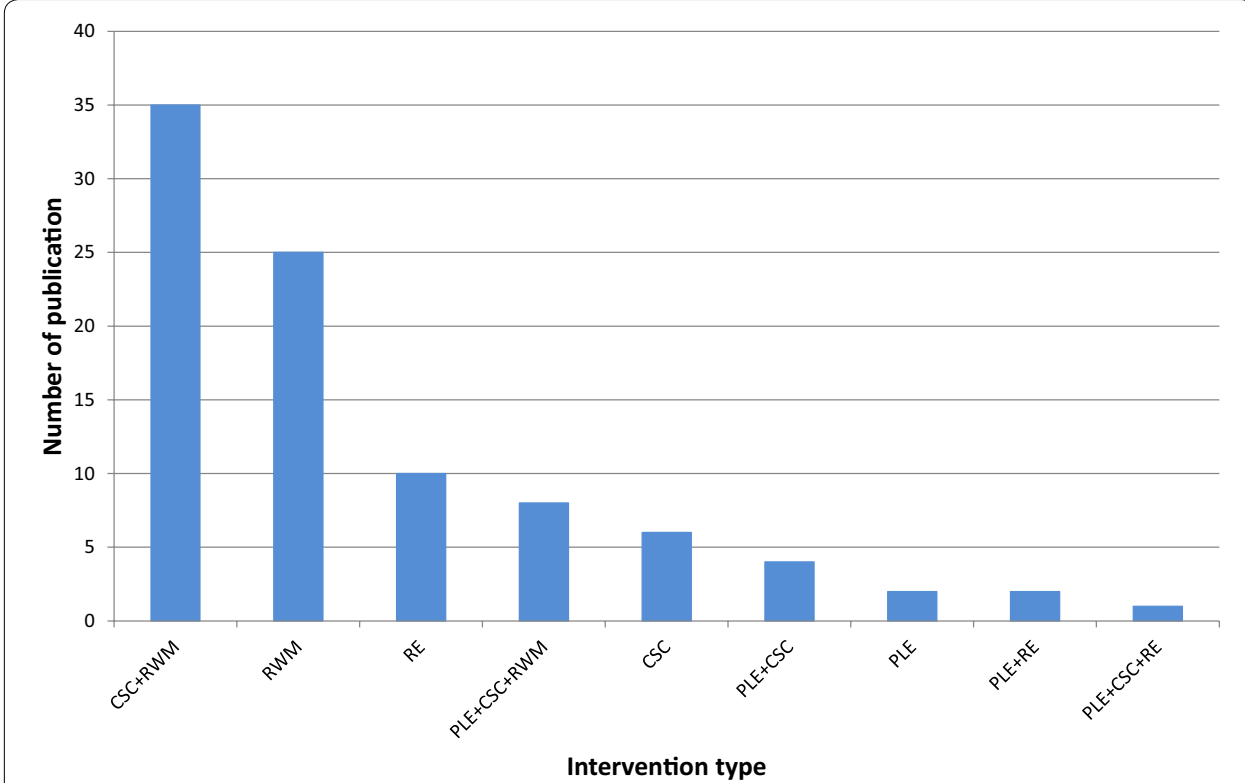

Fig. 2 Number of publications per circularity intervention category (status on 11 June 2018). RWM residual waste management, CSC closing supply chains, PLE product lifetime extension, and RE resource efficiency

computable general equilibrium (CGE) models or other approaches rather than EEIOA (Winning et al. 2017). Apart from the fact that we wanted to focus primarily on the peerreviewed literature, this was an additional reason to exclude this type of studies to focus in the identification of novel methods and best practices in EEIOA-based cases.

\section{Results and Discussion}

We now perform a methodological review of EEIOA-based studies which assess residual waste management, closing supply chains, product lifetime extension, and resource efficiency. Each intervention differs in its approach to splitting and extending sectors in the input-output tables, adjusting technical and final demand coefficients, and incorporating hybrid-unit data.

\subsection{Residual waste management}

Nakamura and Kondo (2002, 2009) introduced the harmonised waste input-output tables, which are used to determine the embodied waste of a certain consumption. The waste input-output analysis (WIOA) consists in a hybrid model constituted by economic and physical units in which are represented explicitly the interaction between industries and waste treatment sectors. This model allows to expand EEIOA in relation to the interdependence between goods and waste disposal.

Several studies applied the WIOA model to measure the direct and indirect waste of consumption at national level, such as Taiwan, France, and UK (Jensen et al. 2013; Liao et al. 2015; Beylot et al. 2016b; Salemdeeb et al. 2016). In a study at sub-national scale, Tsukui et al. $(2011,2017)$ developed an interregional WIOA to quantify the embodied waste generated by consumption patterns in the city of Tokyo. These cases applied a traditional Leontief inverse matrix to estimate the embodied goods and waste of final demand. 
Table 2 Overview of top-10 most cited articles related to the assessment of circularity interventions (status on 11 June 2018)

\begin{tabular}{|c|c|c|c|c|c|c|}
\hline References & Intervention & Region & Sector & IO approach & Outcome & Citations \\
\hline $\begin{array}{l}\text { Wiedmann } \\
\text { et al. (2015) }\end{array}$ & $\mathrm{RE}$ & Global & Multisectoral & MR EEIOA & $\begin{array}{l}\text { Identification } \\
\text { of material } \\
\text { footprint } \\
\text { hotspots at } \\
\text { global scale }\end{array}$ & 218 \\
\hline $\begin{array}{l}\text { Nakamura \& } \\
\text { Kondo (2002) }\end{array}$ & $\begin{array}{l}\text { CSC } \\
\text { RWM }\end{array}$ & Japan & $\begin{array}{l}\text { Waste manage- } \\
\text { ment }\end{array}$ & WIOA & $\begin{array}{l}\text { Evaluation of } \\
\text { environmen- } \\
\text { tal impacts } \\
\text { of waste } \\
\text { treatment } \\
\text { policies }\end{array}$ & 146 \\
\hline $\begin{array}{l}\text { Ferrer \& Ayres } \\
\quad(2000)\end{array}$ & $\begin{array}{l}\text { PLE } \\
\text { CSC }\end{array}$ & France & $\begin{array}{l}\text { Remanufactur- } \\
\text { ing }\end{array}$ & $\mathrm{IOA}$ & $\begin{array}{l}\text { Evaluation of } \\
\text { economic } \\
\text { impacts of } \\
\text { remanufac- } \\
\text { turing sector }\end{array}$ & 78 \\
\hline $\begin{array}{l}\text { Nakamura et al. } \\
\text { (2007a) }\end{array}$ & $\begin{array}{l}\text { CSC } \\
\text { RWM }\end{array}$ & Japan & Metals & WIO-MFA & $\begin{array}{l}\text { Development } \\
\text { of framework } \\
\text { for identify } \\
\text { material } \\
\text { paths along } \\
\text { the supply } \\
\text { chain }\end{array}$ & 72 \\
\hline Duchin (1992) & RWM & United States & $\begin{array}{l}\text { Waste manage- } \\
\text { ment }\end{array}$ & IOA & $\begin{array}{l}\text { Quantification } \\
\text { of waste } \\
\text { disposal } \\
\text { and income } \\
\text { changes for } \\
\text { different } \\
\text { scenarios }\end{array}$ & 66 \\
\hline $\begin{array}{l}\text { Takase et al. } \\
\text { (2005) }\end{array}$ & RWM & Japan & Households & WIOA & $\begin{array}{l}\text { Impacts of } \\
\text { household } \\
\text { consumption } \\
\text { on } \mathrm{CO}_{2} \text { and } \\
\text { landfill use }\end{array}$ & 65 \\
\hline Aye et al. (2012) & $\begin{array}{l}\text { PLE } \\
\text { CSC }\end{array}$ & Australia & Buildings & Hybrid IO-LCA & $\begin{array}{l}\text { Impacts of pre- } \\
\text { fabricated } \\
\text { reusable build- } \\
\text { ing modules } \\
\text { on GHG } \\
\text { emission and } \\
\text { energy }\end{array}$ & 56 \\
\hline $\begin{array}{l}\text { Nakamura and } \\
\text { Kondo (2006) }\end{array}$ & $\begin{array}{l}\text { CSC } \\
\text { RWM }\end{array}$ & Japan & $\begin{array}{c}\text { Electrical home } \\
\text { appliances }\end{array}$ & $\begin{array}{l}\text { Hybrid IO-LCA } \\
\text { \& IO-LCC }\end{array}$ & $\begin{array}{l}\text { Environmen- } \\
\text { tal cost of } \\
\text { end-of-life } \\
\text { scenarios } \\
\text { (landfill, } \\
\text { recycling, } \\
\text { design for } \\
\text { disassembly, } \\
\text { and lifetime } \\
\text { extension) }\end{array}$ & 39 \\
\hline $\begin{array}{l}\text { Kondo and } \\
\text { Nakamura } \\
(2004)\end{array}$ & $\begin{array}{l}\text { PLE } \\
\text { CSC } \\
\text { RWM }\end{array}$ & Japan & $\begin{array}{c}\text { Electrical home } \\
\text { appliances }\end{array}$ & Hybrid IO-LCA & $\begin{array}{l}\text { Environmental } \\
\text { impacts of } \\
\text { end-of-life } \\
\text { scenarios } \\
\text { (landfill, } \\
\text { recycling, } \\
\text { design for } \\
\text { disassembly, } \\
\text { and lifetime } \\
\text { extension) }\end{array}$ & 37 \\
\hline
\end{tabular}


Table 2 (continued)

\begin{tabular}{clllllc}
\hline References & Intervention & Region & Sector & IO approach & Outcome & Citations \\
\hline $\begin{array}{c}\text { Nakamura } \\
\text { (1999a) }\end{array}$ & CSC & Netherlands & $\begin{array}{c}\text { Waste man- } \\
\text { agement \& } \\
\text { recycling }\end{array}$ & WIOA & $\begin{array}{c}\text { Effects of } \\
\text { recycling, } \\
\text { efficiency }\end{array}$ & 36 \\
& & & & collection \\
& & & & $\begin{array}{l}\text { and efficiency } \\
\text { technology }\end{array}$ \\
& & & & recycling \\
\hline
\end{tabular}

Table 3 Summary of EEIOA model characteristic by type of table, units, time and geographical dimensions

\begin{tabular}{lc}
\hline Model characteristic & $\begin{array}{l}\text { Number } \\
\text { of publications }\end{array}$ \\
\hline Table & 82 \\
IOTs & 11 \\
SUTs & \\
Units & 39 \\
Monetary & 5 \\
Physical & 49 \\
Hybrid & \\
Time dimension & 79 \\
Single year & 14 \\
Time series & \\
Geographical dimension & 70 \\
Single region & 23 \\
Multi region & \\
\hline
\end{tabular}

By applying monetary supply-use principles in the WIOA framework, Lenzen and Reynolds (2014) developed a method to construct waste supply-use tables. They considered that a supply-use approach has an advantage because it includes the allocation matrix from WIOA model into the accounting system, which enables the simultaneous generation of industry and commodities multipliers (Lenzen and Rueda-Cantuche 2012). In addition, a supply-use model can distinguish between multiple waste types and treatment methods. The researchers demonstrated that WIOA and WSUA multipliers were equivalents by employing Miyazawa's partitioned inverse method. An application of WSUA was presented by Reynolds et al. (2014), in which the authors assessed the direct and indirect flows of waste generated by intermediate sectors of the Australian economy.

Fry et al. (2016) constructed multiregional waste supply-use tables by using Industrial Ecology Virtual Laboratory as a computational platform (Lenzen et al. 2014). They measured the waste footprint of Australian consumption considering the impacts of imports. The authors also focused on the impacts driven by consumption pattern in each Australian state and territory, which showed the waste footprint at sub-national level.

Similarly, Tisserant et al. (2017) developed a harmonised multiregional solid waste account using coefficients from physical and monetary values from EXIOBASE v2.2.0 
(Tukker et al. 2013; Wood et al. 2015). They collected the data from 35 waste treatment services (measured in tonnes) that were used to calculate global waste footprint and identify the main sectors contributors per country. With the outcome of waste footprint, they evaluated the possibility of achieving targets for material recycling proposed by European Commission in the Circular Economy Package (EC 2018).

By extending satellites accounts, $\mathrm{Li}$ et al. (2013) introduced a wastewater material composition vector that distinguishes the composition of wastewater flows. In addition, Court et al. (2015) incorporated an accounting system for hazards waste materials as an extension of EEIOA.

In a study of landfilling scenarios using waste input-output tables, Yokoyama et al. (2006) created additional sectors of 'landfill mining' and 'gasification'. These activities were evaluated in scenarios of increasing gasification industry demand and adopting new landfill infrastructure. The scenarios required the adaptation of technical coefficients, which imply positive and negative values depending on the interaction between industries. For the final demand, the authors assumed that consumption pattern is proportional to domestic population growth and, then, they fixed the respective final demand values. Their final outcome showed the impacts on $\mathrm{CO}_{2}$ emissions and waste generation under certain assumptions of sustainable waste management.

Duchin $(1990,1992)$ proposed an analysis of waste treatment scenarios by adapting technology matrix and final demand values in EEIOA framework. In her studies, the author computed numerical examples and identified waste disposal in final consumption by adjusting final demand values in a static model. This approach described an entire economy in terms of its sectors and their interrelationships, which account for the environmental impacts.

By converting the monetary values of input-output tables into physical units, Nakamura et al. (2007b) proposed a material flow analysis (MFA) that uses monetary coefficients to express inter-industrial physical flows. The waste input-output material flow analysis (WIO-MFA) was used to trace the final destination of materials and their specific elements through the supply chain (Nakamura and Nakajima 2005; Nakamura et al. 2009; Nakajima et al. 2013; Ohno et al. 2014). For example, in an analysis of metal industry, Ohno et al. (2016) applied the WIO-MFA to assess the material network of metals and alloying elements. For creating the network, they developed three steps: to disaggregate sectors and convert monetary to physical units; to calculate the technical coefficients; and to multiply the input coefficient matrix with two filtering matrices, which are physical flow filter as a binary matrix for excluding non-physical flows and the loss filter matrix that removes inputs that are related to process waste.

From a product-level perspective, Nakamura and Kondo (2006) evaluated the end-oflife scenarios of electric home appliances, landfilling, shredding, recycling, and recycling with design for disassembly, by combining the WIOA framework and life cycle costing analysis. Reynolds et al. (2016b) also demonstrated the use of waste input-output life cycle assessment (WIO-LCA) in the context of New Zealand food waste. They included mass values, economic cost, calories and resources wasted accounts as model inputs. In a recent study, Reutter et al. (2017) combined input-output multipliers with the Australian economic cost of food waste, which can be used to quantify the embodied net surplus of wasted food. 


\subsection{Closing supply chains}

To assess 3R's economic activities (recycling, reuse and reduction), Huang et al. (1994) collected data to include these sectors in a supply-use framework. They applied a traditional Leontief approach in which each new industry produces a single economic commodity. By using such assumption, the authors allocated the monetary flows of recycling and reuse sectors in a new supply-use table that allows to analyse policy initiatives related to closing supply chains.

Nakamura (1999a) applied a similar principle to create a harmonised industry-byindustry framework that accounts for recycling activities. He represented the flow of goods and services, waste, and pollutants among five industries that include recycling sectors. Such activities were expressed by both physical and monetary units because, in many cases, the market value of waste was not represented in accounting system.

In an analysis of electronics waste recycling, Choi et al. (2011) constructed an EEIOA model that collects data for recyclable end-of-life products and related economic sectors. They considered e-waste values in a satellite account that is connected to recycling sectors in a similar way as primary materials are linked to mining industries. The authors then included a new industry and product categories for recycling activities as well as the adjustment of environmental extension to represent the e-waste flows through the supply chain.

For assessing the economic impact of product recovery and remanufacturing in France, Ferrer and Ayres (2000) incorporated the remanufacturing sector in a harmonised industry-by-industry matrix. This harmonised system was adjusted to consider different demands in labour, energy, primary materials, and inputs from others economic sectors. They assumed that the manufacturing and remanufacturing final demand in physical values were equivalent; however, remanufacturing products have a lower price value. They quantified the impacts of the new sector in terms of market share and labour increase.

Beylot et al. (2016b) studied the potential contribution of waste management policies to reduce carbon emissions and resources use. The authors used WIOA obtaining physical units from the French physical supply-use tables. These physical values were used to calculate technological requirement matrices related to waste flows. By considering changes in final demand coefficients, they established scenarios to increase recycling rates and to adopt available best technologies for waste incineration. The scenarios of closing supply chains were extrapolated to evaluate the short-term impacts of recycling policies.

Focusing on the case of Australian consumption, Reynolds et al. (2015) evaluated the effects of non-profit organizations on reducing food waste. In a waste supply-use table, they created a new 'food charity' sector, and extrapolated food waste data from government and industry reports by using a top-down estimation method. According to Reynolds et al. (2016a), this technique allows to estimate waste flow per industry simultaneously but separately in which each waste flow has a unique composition that is defined by the direct production inputs. Such a relationship is provided by the technology matrix, which is also connected to available waste data to construct the new intermediate sector. 
In a study investigating the impact of Portuguese packaging waste management, Ferrão et al. (2014) analysed the effects of municipal waste and recycling strategies on economic added value and job creation. They described four basic types of recycling materials: paper and wood, plastic, glass and metals. For each material type, they considered that the magnitude of recycling sector relative to the respective non-recycling activity is brought by the ratio of the net payback value to the total amount of intrasectoral transactions. The researchers adjusted the ratio of recycling and non-recycling materials in order to evaluate waste management scenarios for packaging alternatives.

In an analysis of tire industry, Rodrigues et al. (2016) modified a waste supplyuse model to recognise the effects of policies related to closing supply chains, such as extended producers responsibility. In this scheme, waste management is financed by compensation that is represented as producers' fees in terms of waste volume processed. The researchers modelled the flow of compensation fees by introducing the financial requirements of waste management under the adapted waste supply-use table. They also adjusted the coefficients of waste treatment intermediate industries in the technical matrix and introduced an exogenous stimulus that is used to compare a reference scenario and the alternative strategy.

To explore the optimal structure of end-of-life treatment and recycling strategies, Kondo and Nakamura (2005) introduced a model that integrates WIOA into a linear programming analysis (WIO-LP). The researchers replaced the fixed constant values of waste input-output tables with an adaptable allocation matrix that can respond to specific constrains. This approach is generally defined as a minimisation problem. For example, Lin (2011) applied the WIO-LP model to analyse the optimal system configuration for reducing environmental loads, such as $\mathrm{CO}_{2}$ emissions from wastewater treatment. The researcher considered a set of constraints to reduce the amount of a certain type of environmental impacts generated by both producing and waste treatment sectors.

In a recent study, Ohno et al. (2017) evaluated the optimal scenarios of steel recycling for end-of-life vehicles in Japan through the integration of linear programming into a waste input-output material flow analysis. They considered quality-oriented scrap recycling and identified which scenarios can contribute to obtain the maximal potential of recovery for alloying elements.

By using industrial accounts for the Taiwanese economy, Chen and Ma (2015) assessed the linkages of industrial material and waste flows at national level. They rearranged the structure of the accounting system to adopt a framework that resembles the WIOA. This accounting system enables us to identify eco-industrial network patterns, for example, by examining the potential of by-products as inputs for other industries.

\subsection{Product lifetime extension}

In an assessment of the Japanese automobile industry, Kagawa et al. (2008) studied the implications of changing passenger vehicle lifetime. They applied a cumulative product lifetime model that is used to describe the patterns of final consumption. This approach is used to adjust the final demand for the scenarios of extending automobile lifetime. The authors then developed a structural decomposition analysis (SDA) with the new scenarios in order to quantify the drivers of end-of-life automobile between certain periods. 
Takase et al. (2005) extended the Japanese household final demand in the WIOA for assessing waste reduction scenarios based on sharing transport services and long-lasting products. These schemes were analysed by adjusting final demand coefficients. In sharing transportation, for example, the authors explored a scenario in which users replace private cars for the use of train. This scenario was expressed by increasing goods in public transport services and decreasing car industry outputs. They changed the coefficient in each scenario and compared the embodied waste disposal and $\mathrm{CO}_{2}$ emissions. In addition, they incorporated potential rebound effects, by assuming a fixed budget for final demand and allocating proportionally the remaining budget to all goods in the new consumption portofolio.

In a further study, Kagawa et al. (2015) adapted WIOA framework to the lifetime distribution model, which is used to forecast secondary material flows demand and supply. They incorporated a stationary stock variable in the lifetime distribution analysis and expressed stocks, discarded and newly purchased products in function of time. These variables were inserted in the final demand, which implies a dynamic function that can be used to predict future demand. In a similar way, secondary supply flows were predicted by the disposal of scraps materials at end-of-life.

Shortly after, Nishijima (2017) used an EEIOA integrated to lifetime distribution analysis for quantifying the effect of extending air conditioners lifetime on $\mathrm{CO}_{2}$ emissions. He calculated the new final demand for household air conditioners by multiplying the production price per air conditioner unit and the number of new air conditioners sold. By adjusting final demand, he performed a structural decomposition analysis to assess the effects of changes final demand, technical and direct $\mathrm{CO}_{2}$ emissions confidents in air conditioners sectors.

Duchin and Levine (2010) introduced an EEIOA framework for estimating the average number of times that a resource passes through each supply chain stage. They established the principles of transforming input-output tables to an absorbing Markov chain (AMC) model based on their mathematical characteristics. For instance, both approaches are matrix-based and are able to represent transaction flows through different economic activities. The monetary flows from the input-output framework are analogous to the AMC's transition states, which represent the probability of a resource to move throughout sectors.

A key study evaluating AMC attributes is that of Eckelman et al. (2012), in which they argued that the AMC approach lays the first stone from the resource extraction as downstream perspective, instead of the upstream consumption-based approach that it is considered in a traditional EEIOA framework.

In a follow-up research, Duchin and Levine (2013) integrated the AMC into a linear programming model that distinguishes key sections of resource-specific network. This integrated model brought detailed insights about the structure of global resource interaction. Furthermore, the model constrained multiregional factors that were adapted to minimise global resource use to satisfy specified final demand.

In a study investigating the distribution of metals over time along the supply chain, Nakamura et al. (2014) established a IO-based dynamic MFA model that considers open-loop recycling and explicitly takes into account scrap quality and losses at production stage. This approach was constructed by converting the monetary coefficients 
of input-output tables into physical representation for the MFA model. Their work on MaTrace model was complemented by Takeyama et al. (2016) study of alloying steel elements in Japan. They applied MaTrace framework to demonstrate the potential reduction in alloying elements dissipation.

More recently, Pauliuk et al. (2017) developed the dynamic approach in a multiregional context, which was used to determine regional distribution and losses of steel production throughout multiple lifetime stages. They described their 'MaTrace' model as a supply-driven approach that traces down specific materials in life cycles of multiples products and complement the life cycle perspective, which is compared with other techniques, such as AMC and Ghosh inverse matrix. The researches also introduced a material-based circularity indicator by considering the cumulative mass of material present in the system over a certain time interval in terms of an ideal reference case.

\subsection{Resource efficiency}

In an analysis of material use for Japanese household consumption, Shigetomi et al. (2015) decomposed the household final demand into the consumption expenditures by householder age bracket. The disaggregated expenditures were used to quantify the material intensity of each household group, which represented the material hotspots of final demand. The authors identified the major contributors to the material footprint and projected future consumption trend based on a linear regression model. This analysis assumed that future household size will be proportional to the predicted population growth.

Skelton and Allwood (2013) explored the impacts of material efficiency on key steelusing industries by the application of multiregional input-output (MRIO) approach. They focused on an upstream perspective to seek opportunities through the supply chain of steel. A diagonal final demand vector was applied to identify the final destination of steel output from each sector. They assessed the major contributors to the footprint in terms of their potential incentives to implement material efficiency strategies. They measured such incentives in a supply-side approach based on the Ghosh inverse matrix (Miller and Blair 2009). This method allows to quantify the effects of changing the value added. The researchers performed price changes assuming that carbon tax scenarios are implemented. The fixed prices were applied to the system in order to measure the variation in the share of input expenditure that goes on the steel sector, which expresses the incentives of each industry for incorporating material efficiency practices.

Giljum et al. (2015) analysed geographical trade patterns identifying the embedded materials on a bilateral basis. They extended the MRIO model by adding material extraction data. This dataset was grouped into four broad types: metals, minerals, fossil fuels and biomass. Each classification was used to calculate the domestic material consumption and raw material consumption per country. In the same way, Wiedmann et al. (2015) calculated material footprint time series that were used to represent the changes of resource productivity at global level. They presented a multivariate regression analysis for countries to understand the driving forces of national material footprints. A broader perspective has been adopted by Tukker et al. (2016) who estimated resource footprint considering the indicator dashboard of resource efficiency, which includes carbon, water, energy and land metrics (EC 2011). The authors correlated each resource footprint with 
quality life indicators, namely human development index and happy development index, bringing a social dimension to resource efficiency measures.

\section{Synthesis of EEIOA frameworks on the assessment of circularity interventions}

In the following section, we synthetise the findings from the literature review in terms of the current application of EEIOA in a circular economy context. To illustrate the further development and best practices of such methods, we consider a simplified waste supplyuse analysis (WSUA) based on Rodrigues et al. (2016). Although we found the application of traditional EEIOA and other hybrid models, we use the waste input-output approach because it shows a suitable framework for creating end-of-life scenarios, which are usually linked to the basis of circular strategies (Kirchherr et al. 2017).

The majority of the studies suggested that WIOA can be applied to measure effectively the resource flows of circularity interventions. In addition, WIOA can benefit from a supply-use approach which can express the interaction of products and industries in a higher level of detail (Lenzen and Reynolds 2014).

Figure 3 shows a basic waste supply-use table that contains three main parts: final demand vector $(y)$, technology matrix $(A)$ and intensity vector $\left(b^{\prime}\right)$. The $y$-vector is subdivided into final consumption of products $\left(y^{P}\right)$ and final waste generation $\left(y^{W}\right)$. The $A$ -matrix is comprised of a set of submatrices that account for the direct requirements of products or services $(P)$, sectors or industries $(S)$, waste $(W)$, and waste treatment or recycling sectors $(T)$. The $b^{\prime}$-vector shows the element of direct impact coefficients that correspond to the production intensities of the $S$ and $T$ sectors ( $e^{S}$ and $e^{T}$, respectively). We can assess the effects of incorporating circularity interventions by adjusting final

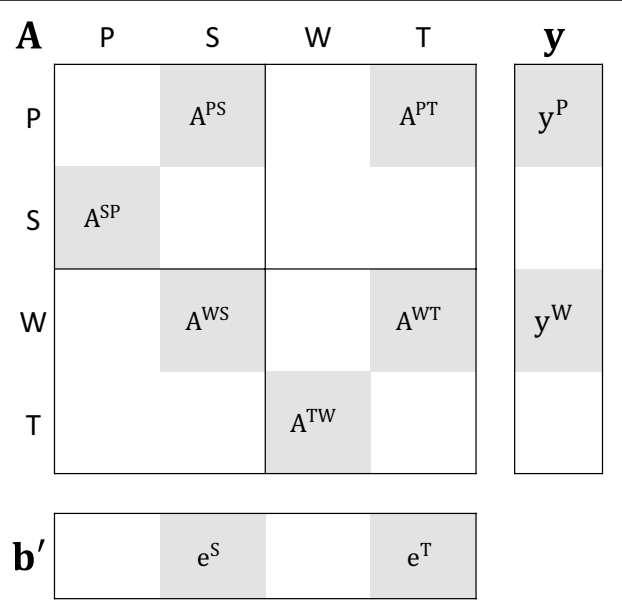

Fig. 3 Simplified waste supply-use table. $y=$ final demand vector; $A=$ technology matrix; $b^{\prime}=$ intensity vector. $P=$ product or service, $S=$ sector or industry, $W=$ waste, $T=$ waste treatment or recycling activity. $y^{P}$ elements are monetary values (M.EURO). $y^{W}$ elements are physical units (tonnes). $A^{\mathrm{PS}}$ and $A^{\mathrm{SP}}$ elements are coefficients from monetary units (M.EUR/M.EUR). $A^{\text {WS }}$ elements are coefficients from physical and monetary units (tonnes/M.EUR). $A^{\text {TW }}$ and $A^{\text {WT }}$ elements are coefficients from physical units (tonnes/tonnes). $A^{\mathrm{PT}}$ elements are coefficients from monetary and physical units (M.EUR/tonnes). $e^{5}$ elements represent coefficients from physical values, depending on the environmental pressure, and monetary units (e.g. $\mathrm{CO}_{2}$ tonnes/M.EUR). $e^{T}$ elements represent coefficients from physical values, depending on the environmental pressure, and physical units (e.g. $\mathrm{CO}_{2}$ tonnes/tonnes). Empty cells contain zeros 
demand and technology coefficients. Several authors applied changes in $y$-vector and $A$ -matrix to explore the scenarios of enhancing waste treatment and recycling activities (for example, Yokoyama et al. 2006; Beylot et al. 2016a, 2018). In many cases, representing these sectors would require the extension of intermediate demand to account explicitly for the specific flows of each circular strategy.

Considering a reference scenario $\left(y, A, b^{\prime}\right)$, it is possible to adapt the intermediate flows and final demand coefficients to represent the changes of new circularity actions $\left(y^{\text {alt }}, A^{\text {alt }}, b^{\text {alt }}\right)$. We then can calculate the embodied impacts of the reference scenario $(m)$ and the alternative circular strategy $\left(m^{\text {alt }}\right)$ by a traditional Leontief inverse (Miller and Blair 2009), as is shown in Eq. (1)-(2):

$$
\begin{aligned}
& m=b^{\prime}(I-A)^{-1} y ; \\
& m^{\text {alt }}=b^{\text {alt }}\left(I-A^{\text {alt }}\right)^{-1} y^{\text {alt }} .
\end{aligned}
$$

The net effect of circularity interventions $(\Delta m)$ can be quantified by the difference of $m$ and $m^{\text {alt }}$ (see Eq. 3). This net impact could represent a measure for the potential effect of a specific circularity scenario. For example, if we analysed the implications of a certain circularity action on carbon footprint and the net effect would be a positive value (i.e. $\Delta m>0$ ), it means that the alternative circularity scenario has less impact than the reference stage on the embodied carbon emissions. Such avoided impact from the application of a circularity intervention could be used as point of comparison between different scenarios.

$$
\Delta m=\left(m-m^{\text {alt }}\right) .
$$

We can synthetise the lessons from the literature to determine which are the best practices for constructing an alternative final demand $\left(y^{\text {alt }}\right)$, technology matrix $\left(A^{\text {alt }}\right)$, and intensity $\left(b^{\prime a l t}\right)$ that determine the effects of each circularity intervention. Based on the literature review, we then deduce the causality sequence of adapting scenarios for residual waste management, closing supply chains, product lifetime extension, and resource efficiency. The following sub-sections can be used as a reference point for analysing specific scenarios of circularity transition.

We now focus on the description of primary and secondary sequences for each circularity action. Primary sequence refers to the first element of an EEIOA that can be adapted in order to represent the implementation of a circularity intervention. Following a causality chain, the secondary sequence denotes the first order of indirect impacts in response to the primary stimulus. We schematise such sequences in order to demonstrate the adjustment of waste supply-use tables for modelling each circularity alternative. Figure 4 indicates casual links as follows: primary sequence (green square, solid line border ' - '), secondary sequence (red square, dashed line border '---'), the up arrow (' $\uparrow$ ') represents a relative increment of the technical coefficients on A-matrix, the down arrow (' $\downarrow$ ') indicates a relative reduction in the technical coefficients on $A$-matrix, and the up-down arrows (' $\uparrow \downarrow$ ') represents sequences in which technical coefficients can be increasing or decreasing in different sectors or industries due to the same causal link. 
Residual waste management
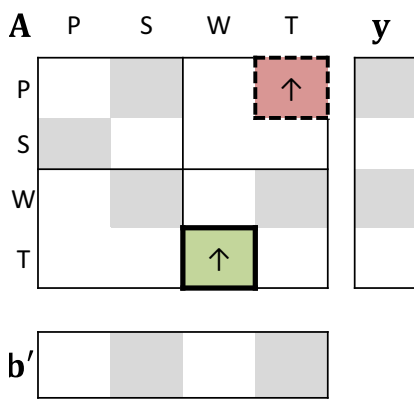

$\mathbf{a}$

\section{Product lifetime extension}
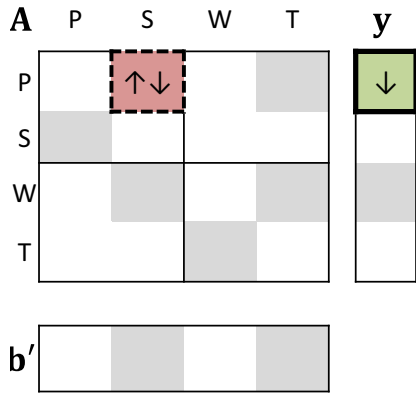

c
Closing supply chains
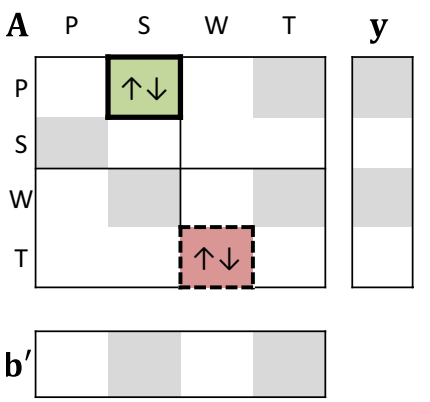

b

Resource efficiency
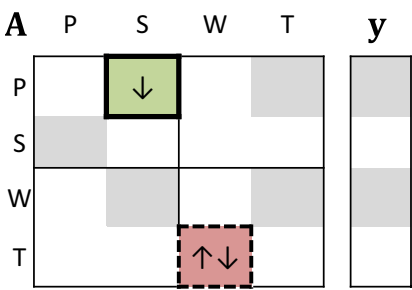

b

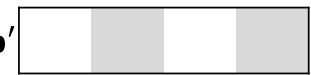

d

Fig. 4 Modelling causality sequence of $\mathbf{a}$ residual waste management, $\mathbf{b}$ closing supply chains, $\mathbf{c}$ product lifetime extension, and $\mathbf{d}$ resource efficiency. $y=$ final demand vector, $A=$ technology matrix, $b^{\prime}=$ intensity vector. $P=$ product or service, $S=$ sector or industry, $W=$ waste, $T=$ waste treatment or recycling activity. Green square with solid line border ('_- ' $)$ indicates primary sequence, and red square with dash line border $\left({ }^{\prime}---'\right)$ represents secondary sequence. ' $\uparrow$ ' indicates a relative increase in A-matrix coefficients, ' $\downarrow$ ' indicates a relative decrease in A-matrix coefficients, ' $\uparrow \downarrow$ ' indicates a simultaneous change in different sectors or industries caused by the same causal link

As in Nakamura and Kondo (2002), the $A$-matrix might contain negative values that show the causality sequence of waste flows thought economic activities. For instance, the inputs of recycling activities can be expressed as negative inputs of treatment sectors that would be required if recycling processes were not available (Nakamura and Kondo 2002).

\subsection{Modelling residual waste management}

Residual waste management can be modelled by adjusting the amounts of waste treated by specific waste treatment sectors. Several authors created new waste treatment with improved technology (for example, Nakamura and Kondo 2009; Liao et al. 2015; Beylot et al. 2016b), which could be added to a waste supply-use table. These activities would require to augment their inputs from the rest of the economy in order to process the quantity of waste established in a specific circularity scenario (Yokoyama et al. 2006).

Figure $4 \mathrm{a}$ shows the causality sequence of changing the $A$-matrix for reducing waste scenarios. As primary sequence, wasted materials require to be absorbed by waste 
treatment sectors ( $\uparrow$ in $A^{\mathrm{TW}}$ elements). A secondary effect of such action is an increase on the direct requirements of waste treatment sectors in order to satisfy the new intermediate demand ( $\uparrow$ in $A^{\mathrm{PT}}$ coefficients). As a consequence of rising production, waste disposal from waste treatment activities and their suppliers are expected to increase ( $\uparrow$ in $A^{\mathrm{TW}}$ and $A^{\mathrm{WS}}$ elements). This sequence appears to create an ongoing loop where absorbing waste would lead to increase waste disposal in order to process the new residuals. However, disposal would need to be constrained by the processing capacity of waste treatment sectors. In our present framework, we do not focus on how capacity constraints should be modelled explicitly; nevertheless, we consider it to be an important aspect for future studies.

It is important to notice that, in some cases, the causality sequence could not be represented by changes in the A-matrix block. For example, increasing $A^{\mathrm{TW}}$ coefficients might not lead to an increment of $A^{\mathrm{PT}}$ coefficients directly. Instead, a secondary sequence can be observed in changes on the intermediate demand block of waste treatment inputs.

\subsection{Modelling closing supply chains}

Closing supply chains can be modelled by changing input and output coefficients to closed-loop activities, such as reuse and recycling sectors. These sectors can be represented as new end-of-life systems that would use waste outputs from industries as inputs to generate a usable product for the economy (Nakamura and Kondo 2006; Chen and Ma 2015). In many cases, such new activities would be added to EEIOA in order to model specific material recycling (for example, Ferrer and Ayres 2000; Choi et al. 2011; Reynolds et al. 2015).

A common assumption is that closing supply chains would drive the reduction in extracting virgin materials as a consequence of their replacement with secondary circular flows (Ferrer and Ayres 2000). This substitutional approach can be modelled by the replacement of specific commodities in the use matrix of industries by secondary materials, components, etc. (i.e. $\uparrow \downarrow$ in $A^{\mathrm{PS}}$ coefficients).

Figure $4 \mathrm{~b}$ presents the causality sequence of closing supply chain scenarios. The primary sequence of closed-loop strategies would imply to adapt the use matrix of a specific industry. Assuming that industry $(S)$ would replace a primary product $\left(P^{\prime}\right)$ for a secondary material from a recycling activity $\left(P^{\prime \prime}\right)$, then the coefficients of the $A^{\mathrm{PS}}$-matrix would decrease for the virgin materials ( $\downarrow$ for $a^{\mathrm{P} / \mathrm{s}}$ ). Likewise, the direct requirements of $\mathrm{S}$ would rise for the input of secondary goods $\left(\uparrow\right.$ for $\left.a^{\mathrm{P} / \mathrm{s}}\right)$. A proportional exchange between $P^{\prime}$ and $P^{\prime \prime}$ can be expressed by monetary terms, if the prices of both products are fixed, as well as by direct substitution in physical units (Ferrer and Ayres 2000; Ferrão et al. 2014). Following the secondary sequence, we observe the adjustment of waste fractions treated by waste treatment industries ( $\uparrow \downarrow$ in $A^{\mathrm{TW}}$ elements). Such an effect is considered because the replacement of $P^{\prime}$ for $P^{\prime \prime}$ could adapt as well the waste generated by industry $S$, and, then, changing direct requirements from waste treatment sectors in order to dispose the new fractions of waste.

\subsection{Modelling product lifetime extension}

The scenarios of extending product lifetime can be modelled by combining an adjusted final demand and the input coefficients in production sectors, next to probably a higher 
input of maintenance activities. In general, it is expected that the extension of product lifetime would decrease the quantity of goods consumed by final demand (Kagawa et al. 2009; Nishijima 2017). Therefore, a primary effect of prolonging product lifetime would involve a reduction in final consumption on a certain product $\left(y_{i}^{P}\right)$.

Figure 4c illustrates the causality chain of product lifetime extension. Assuming that a product $i$ is designed to maximise its durability, the demand of such good would expect to decrease $\left(\downarrow\right.$ for $y_{i}^{P}$ ). Although this effect might imply an improvement of environmental performance from reducing the consumption of product $i$, the potential economic savings could be expended in other goods or services thus obtaining a rebound (Zink and Geyer 2017).

A possible approach to account for these rebound effects is proposed by Takase et al. (2005). They suggested that the total expenditure of new final demand $\left(x^{P}\right)$ would remain the same as total consumption in the reference scenario $(x)$. By applying their assumption, we can distribute a leftover budget proportionally to the rest of goods and then include a quick estimation for the rebound effect in the alternative final demand $\left(y^{P^{*}}\right)$, as is shown in Eq. (4):

$$
y^{P^{*}}=y^{P}\left(\frac{x}{x^{P}}\right) .
$$

As a secondary effect, it is possible that extending product lifetime could potentially require the adjustment of the production recipe, which leads to change in the input requirements of industries (Bakker et al. 2014; den Hollander et al. 2017b). However, there are only limited opportunities for consumers to prolong their product's lifetime when the product design is unchanged.

Depending on the product design, some industries might require to increase their material inputs in order to manufacture a more durable product (Murray et al. 2015). This operational adjustment is expressed in Fig. 4c by the simultaneous increment and reduction in technology matrix coefficients (in $A^{\mathrm{PS}}$ ). For example, if a change of the production recipe for obtaining a durable good would require to reduce the input of commodity $i$ and to increase the input of product $k$, then we can model such adjustments on the $A^{\mathrm{PS}}$-matrix (by $\uparrow$ for $a_{k, j}^{\mathrm{PS}}$ and $\downarrow$ for $a_{i, j}^{\mathrm{PS}}$ ).

\subsection{Modelling resource efficiency}

In comparison with the previous interventions, resource efficiency is the least studied of circularity actions from an EEIOA perspective (see Fig. 2), and it can be one of the most interesting in terms of future development of EEIOA method. We found that studies related to resource efficiency are mostly focused on the calculation of resource footprint as an aggregated value (for example, Giljum et al. 2015; Wiedmann et al. 2015; Tukker et al. 2016). However, resource footprint by itself does not capture if resource efficiency policies would be beneficial for reducing the extraction material from the environment or if it would contribute to minimise waste disposal. For assessing the impacts of resource efficiency measures, we can consider the effects of such intervention by lowering input coefficients at the same output.

Figure $4 \mathrm{~d}$ presents the casual links of resource efficiency actions. In terms of primary sequence, it is possible that the application of material efficiency can lead to reduce 
the input requirements of economic activities where such intervention is implemented ( $\downarrow$ in $A^{\mathrm{PS}}$ coefficients). In a similar sequence as in modelling closing supply chain (see Sect. 4.2), a secondary implication of changes in $A^{\mathrm{PS}}$ can be expected in the operational changes of waste treatment, in which the technical coefficients of waste treatment sectors can be adapted as a response of variations in waste disposal ( $\uparrow \downarrow$ in $A^{\mathrm{TW}}$ elements). To compare different scenarios, it is important to consider an accounting system in which the $A^{\mathrm{PS}}$-matrix is expressed in physical terms because the use of monetary units as proxy can misrepresent physical reality (Dietzenbacher 2005).

\section{Discussion}

In this review, our purpose was to critically evaluate the current application of EEIOA on the assessment of circularity interventions. We now focus on the main contributions and limitations of EEIOA in order to bring a possible direction for the development of such method in the assessment of circular strategies.

From the reviewed studies, we found a common agreement on how the assessment of circularity can be benefit from the development of EEIOA in which end-of-life scenarios are integrated. Such models usually are comprised of hybrid units in which secondary and waste flows can be considered (for example, Nakamura and Kondo 2009; Lenzen and Reynolds 2014). In addition, identifying these flows at multiregional scale has led to a better understanding of the impacts of international trade on resource and waste footprints in specific countries (as in Duchin and Levine 2013; Wiedmann et al. 2015; Fry et al. 2016; Tukker et al. 2016; Tisserant et al. 2017).

On the other hand, we observed that a major aspect to develop is the representation of flows as economic transactions. The monetary values of input-output tables could not address effectively the allocation of resource flows because the monetary values per physical units can differ significantly in several supply chains (Weisz and Duchin 2006). This variation is caused by the assumption of an average price for materials with diverse physical properties and qualities (Tukker et al. 2016).

Price variation could become a critical factor in EEIOA with high sectorial and product aggregation (Wiedmann et al. 2015). It is likely to be a limitation for adequately tracing specific resource flows. For instance, if we assessed the recycling and reuse flows of a specific material such as 'recovered aluminium', input-output tables with broad classification of materials and industries (e.g. 'metal products' and 'mining sector') would assume that the price per physical value of 'recovered aluminium' is equivalent to the value of aggregated 'metal products'. This example shows that a highly aggregated EEIOA could in many cases be too limited to model specific material flows.

To avoid the deficiency in resolution of some EEIOA models, a reasonable approach could be to disaggregate products and sectors in more detailed categories. The new classification may contribute to monitor specific resource flows in a circular economy model (as shown by Choi et al. 2011; Li et al. 2013). However, disaggregating sectors in EEIOA presents a challenge by itself because sectoral data may not be available at the required level of detail. This is particularly the case in waste input-output frameworks, in which many studies show a limited dataset to split and link waste treatment sectors to the rest of the economy (Salemdeeb et al. 2016). 
According to the studies, a lack of data sets for waste and material recovery could represent an issue in terms of waste valuation. Several authors recognised a deficiency for accounting the economic value of waste as this could be lower or absent in the EEIOA model (Nakamura 1999a; Liao et al. 2015). The lack of economic valuation renders input-output accounts incomplete and, in some cases, leads to the underestimation of the embodied waste generated by final demand. For example, in the study of the Australian waste footprint by Fry et al. (2016), waste flows related to overseas production could not be considered due to the lack of waste values in other regions. This led to an underestimation of waste footprint resulting from Australian consumption by at least 1.5 million tonnes.

Underestimating waste generation may be caused by three aspects (Tisserant et al. 2017). First, some waste treatment sectors might not be included in the EEIOA model. Second, a standard EEIOA does not consider informal or illegal activities that could affect the estimation of waste footprint. Finally, EEIOA might not capture some of the flows that are not linked to monetary or physical transactions between sectors (i.e. direct reuse flows). In general, these aspects have an impact on the quality of waste data availability in many countries, which can be a significant source of uncertainty.

To address the lack of specific-sectoral data, proxies that can be used to integrate the values of circular strategies into the EEIOA framework could be estimated. For instance, to identify the patterns of industrial waste disposal, Reynolds et al. (2016b) suggested that the shares of waste generation in New Zealand presented the same trend as others developed economies (e.g. UK and Australia) and, then, used a proxy for the estimation of waste generation. In many cases, this type of assumption introduces uncertainties that may affect the analysis reliability (Ohno et al. 2016). Although the importance of uncertainties is considered in the literature (Wiedmann 2009), most of the reviewed studies mention the level of uncertainty without addressing it in much detail, and it brings a recurrent issue about data reliability of analysing circular economy interventions with EEIOA.

In terms of modelling circularity scenarios, EEIOA may be of limited use when assessing environmental implications in the future (de Koning 2018). For example, by fixing technical coefficients of a circular economy scenario, EEIOA cannot capture the volume effects on prices as well as price effects on the use of certain products. Without additional model components (see, for example, Gibon et al. 2015), EEIOA has also limited opportunities to represent changes of energy systems in the future with environmental impacts that are different from the current way of production. Moreover, there is no direct feedback effect from nature to the economy in standard EEIOA, which restricts the assessment of different circularity gains.

\section{Conclusions}

This article presented a review of EEIOA-based studies that assessed the economic and environmental implications of residual waste management, closing supply chains, product lifetime extension, and resource efficiency interventions. We evaluated the selected articles based on their methodological characteristics in order to synthetise the main EEIOA-based frameworks used to analyse each circularity intervention. Furthermore, our results led 
to a point of reference for modelling future circular strategies at macro-scale by applying EEIOA.

By considering a simplified waste supply-use model, we explained the causality sequence of modelling circularity interventions. For residual waste management, a waste treatment action can be modelled by augmenting the values of waste absorbed by a certain waste treatment sector, which in turn requires more inputs from the rest of the economy in order to process the new amount of waste disposal.

Closing supply chains can be assessed by adjusting input and output coefficients for industries that adopt closed-loop strategies, which are related to the replacements of virgin materials with secondary circular flows. In addition, these interventions require to specify new sectors in the EEIOA model if the circular activities are not explicitly expressed.

Product lifetime extension can be modelled by adapting the final demand coefficients by expecting a reduction in final consumption. However, it is important to consider a potential rebound effect of prolonging product lifetime caused by the expenditures on other product or service categories from the savings on final demand. Furthermore, modelling product lifetime extension might involve accounting for potential changes of the production recipe of durable goods.

Resource efficiency intervention can be analysed by reducing input coefficients while maintaining the output. Such action could minimise the input requirements of economic activities in which the intervention is applied, and it can be used to model the structural changes in a technology matrix caused by resource efficiency strategies.

We observe that the development of waste input-output analysis (WIOA) will dominate the assessment of circularity transition, because it is the most suitable framework to link the flows of waste and the rest of the economy in an EEIOA system. However, WIOA is constrained by the monetary flows in EEIOA (Nakamura and Kondo 2009), which can be considered a major limitation for the analysis of circular strategies, especially in the case of residual waste management, due to the lack of valuing waste. This challenge can be avoided by future applications of physical and hybrid tables that can be used to analyse the potential impacts of material efficiency and secondary flows more accurately (Tisserant et al. 2017).

The recent development of hybrid-unit input-output and supply-use tables, in which tangible products and waste types are expressed in physical units (i.e. mass) and service sectors in monetary units (for example, Merciai and Schmidt 2018), will advance the modelling of circularity interventions in a consistent framework. In addition, detailed sectoral data could enable the assessment of circular strategies such as re-use, remanufacturing, and refurbishment (Ellen MacArthur Foundation 2013). Combining both aspects, hybrid tables and detailed production data, would allow an improvement of current EEIOA models for assessing the economic and environmental implications of a circularity transition.

\section{Additional file}

Additional file 1. List of reviewed publications and bibliometric analysis. 
input-output analysis; IOA: input-output analysis; MFA: material flow analysis; WIOA: waste input-output analysis; WIOMFA: waste input-output material flow analysis; LCA: life cycle assessment; LCC: life cycle costing assessment; IO-LCA: hybrid input-output life cycle assessment; IO-LCC: hybrid input-output life cycle costing analysis; IOTs: input-output tables; SUTs: supply-use tables; WSUA: waste supply-use analysis; WIO-LCA: waste input-output life cycle assessment; 3R's: recycling, reuse, reduce; WIO-LP: waste input-output linear programming analysis; SDA: structural decomposition analysis; AMC: absorbing Markov chain model; MRIO: multiregional input-output model; P: product or service; S: sector or industry; W: waste; T: waste treatment sector.

\section{Authors' contributions}

GAAH, CPSS, and AT planned the literature review. GAAH, CPSS, FD, JFDR, and AT contributed to the design of the manuscript. GAAH, CPSS, FD, JFDR, and AT contributed to the interpretation of the results. GAAH wrote the manuscript with input from all authors. All authors read and approved the final manuscript.

\section{Acknowledgements}

We thank two anonymous reviewers that have contributed to improving the quality of the paper.

\section{Competing interests}

The authors declare that they have no competing interests.

\section{Ethics approval and consent to participate}

Not applicable.

\section{Funding}

Glenn A. Aguilar-Hernandez is part of the Circular European Economy Innovative Training Network (CircEuit), funded by the European Commission under the Horizon 2020 Marie Skłodowska Curie Action 2016 (Grant Agreement Number 721909)

\section{Publisher's Note}

Springer Nature remains neutral with regard to jurisdictional claims in published maps and institutional affiliations.

Received: 21 December 2017 Accepted: 14 June 2018

Published online: 28 June 2018

\section{References}

Andersen MS (2007) An introductory note on the environmental economics of the circular economy. Sustain Sci 2:133-140. https://doi.org/10.1007/s11625-006-0013-6

Aye L, Ngo T, Crawford RH et al (2012) Life cycle greenhouse gas emissions and energy analysis of prefabricated reusable building modules. Energy Build 47:159-168. https://doi.org/10.1016/j.enbuild.2011.11.049

Bakker C, Wang F, Huisman J, den Hollander M (2014) Products that go round: exploring product life extension through design. J Clean Prod 69:10-16. https://doi.org/10.1016/j.jclepro.2014.01.028

Bastein T, Roelofs E, Rietveld E, Hoogendoorn A (2013) Opportunities for a Circular Economy in the Netherlands

Beylot A, Boitier B, Lancesseur N, Villeneuve J (2016a) A consumption approach to wastes from economic activities. Waste Manag 49:505-515. https://doi.org/10.1016/j.wasman.2016.01.023

Beylot A, Vaxelaire S, Villeneuve J (2016b) Reducing gaseous emissions and resource consumption embodied in french final demand: how much can waste policies contribute? J Ind Ecol 20:905-916. https://doi.org/10.1111/jiec.12318

Beylot A, Boitier B, Lancesseur N, Villeneuve J (2018) The Waste Footprint of French Households in 2020. J Ind Ecol 22:356-368. https://doi.org/10.1111/jiec.12566

Bocken NMP, de Pauw I, Bakker C, van der Grinten B (2016) Product design and business model strategies for a circular economy. J Ind Prod Eng 33:308-320. https://doi.org/10.1080/21681015.2016.1172124

Bocken NMP, Ritala P, Huotari P (2017) The circular economy: exploring the introduction of the concept among S\&P 500 firms. J Ind Ecol. https://doi.org/10.1111/jiec.12605

Chen P-C, Ma H (2015) Using an industrial waste account to facilitate national level industrial symbioses by uncovering the waste exchange potential. J Ind Ecol 19:950-962. https://doi.org/10.1111/jiec.12236

Choi T, Jackson RW, Green Leigh N, Jensen CD (2011) A baseline input-output model with environmental accounts (IOEA) applied to E-waste recycling. Int Reg Sci Rev 34:3-33. https://doi.org/10.1177/0160017610385453

Court CD, Munday M, Roberts A, Turner K (2015) Can hazardous waste supply chain "hotspots" be identified using an input-output framework? Eur J Oper Res 241:177-187. https://doi.org/10.1016/j.ejor.2014.08.011

de Koning A (2018) Creating global scenarios of environmental impacts with structural economic models. Leiden University, Leiden

den Hollander MC, Bakker CA, Hultink EJ (2017a) Product design in a circular economy: development of a typology of key concepts and terms. J Ind Ecol. https://doi.org/10.1111/jiec.12610

den Hollander MC, Bakker CA, Hultink EJ (2017b) Product design in a circular economy: development of a typology of key concepts and terms. J Ind Ecol 21:517-525. https://doi.org/10.1111/jiec.12610

Dietzenbacher E (2005) Waste treatment in physical input-output analysis. Ecol Econ 55:11-23. https://doi.org/10.1016/j. ecolecon.2005.04.009

Duchin F (1990) The conversion of biological materials and wastes to useful products. Struct Chang Econ Dyn 1:243-261. https://doi.org/10.1016/0954-349X(90)90004-R

Duchin F (1992) Industrial input-output analysis: implications for industrial ecology. Proc Natl Acad Sci 89:851-855 
Duchin F, Levine SH (2010) Embodied resource flows and product flows: combining the absorbing markov chain with the input-output model. J Ind Ecol 14:586-597. https://doi.org/10.1111/j.1530-9290.2010.00258.x

Duchin F, Levine SH (2013) Embodied resource flows in a global economy: an approach for identifying the critical links. J Ind Ecol 17:65-78. https://doi.org/10.1111/j.1530-9290.2012.00498.x

EC (2011) Communication from the Commission to the European Parliament, the Council, the European Economic and Social Committee and the Committee of the Regions: Roadmap to a Resource Efficient Europe

EC (2015) Communication from the Commission to the European Parliament, the Council, the European Economic and Social Committee and the Committee of the Regions: closing the loop-An EU action plan for the Circular Economy. Brussels

EC (2018) Circular economy package. Four legislative proposals on waste

Eckelman MJ, Reck BK, Graedel TE (2012) Exploring the global journey of Nickel with Markov chain models. J Ind Ecol 16:334-342. https://doi.org/10.1111/j.1530-9290.2011.00425.x

EEA (2016) Circular economy in Europe—developing the knowledge base. Luxembourg

Elia V, Gnoni MG, Tornese F (2017) Measuring circular economy strategies through index methods: a critical analysis. J Clean Prod 142:2741-2751. https://doi.org/10.1016/j.jclepro.2016.10.196

Ellen MacArthur Foundation (2013) Toward the circular economy. Technical Report. https://urldefense.proofpoint.com/ v2/url?u=https-3A_www.ellenmacarthurfoundation.org_publications_towards-2Dthe-2Dcircular-2Deco nomy-2Dvol-2D1-2Dan-2Deconomic-2Dand-2Dbusiness-2Drationale-2Dfor-2Dan-2Daccelerated-2Dtransit on\&d=DwIFAg\%26c=vh6FgFnduejNhPPDOfl_yRaSfZy8CWbWnlf4XJhSqx\%26\%26r=_tDouL3h-1LDiBK93Wj 27DvOJuSTpUjtL_R9oBJNIXM\%26m=ub70OkfrYAmuhgSQ103pJHoYxgAxBmUXrSIZjPoSz3k\%26s=UL8EMatkeU quwA4v5AjOqtfYJfHYp6fNyD-rzPD1TW1\%26e=

Ferrão P, Ribeiro P, Rodrigues J et al (2014) Environmental, economic and social costs and benefits of a packaging waste management system: a Portuguese case study. Resour Conserv Recycl 85:67-78. https://doi.org/10.1016/j.resco nrec.2013.10.020

Ferrer G, Ayres RU (2000) The impact of remanufacturing in the economy. Ecol Econ 32:413-429. https://doi.org/10.1016/ S0921-8009(99)00110-X

Fry J, Lenzen M, Giurco D, Pauliuk S (2016) An Australian multi-regional waste supply-use framework. J Ind Ecol 20:12951305. https://doi.org/10.1111/jiec.12376

Geissdoerfer M, Savaget P, Bocken NMP, Hultink EJ (2017) The circular economy—a new sustainability paradigm? J Clean Prod. https://doi.org/10.1016/j.jclepro.2016.12.048

Geng Y, Fu J, Sarkis J, Xue B (2012) Towards a national circular economy indicator system in China: an evaluation and critical analysis. J Clean Prod 23:216-224. https://doi.org/10.1016/j.jclepro.2011.07.005

Geng Y, Sarkis J, Ulgiati S (2016) Sustainability, wellbeing, and the circular economy in China and worldwide. Science 80:76-79

Ghisellini P, Cialani C, Ulgiati S (2016) A review on circular economy: the expected transition to a balanced interplay of environmental and economic systems. J Clean Prod 114:11-32. https://doi.org/10.1016/j.jclepro.2015.09.007

Gibon T, Wood R, Arvesen A et al (2015) A methodology for integrated, multiregional life cycle assessment scenarios under large-scale technological change. Environ Sci Technol 49:11218-11226. https://doi.org/10.1021/acs. est. 5 b01558

Giljum S, Bruckner M, Martinez A (2015) Material footprint assessment in a global input-output framework. J Ind Ecol 19:792-804. https://doi.org/10.1111/jiec.12214

Huang GH, Anderson WP, Baetz BW (1994) Environmental input-output analysis and its application to regional solidwaste management planning. J Environ Manag 42:63-79

lacovidou E, Velis CA, Purnell P et al (2017) Metrics for optimising the multi-dimensional value of resources recovered from waste in a circular economy: a critical review. J Clean Prod 166:910-938. https://doi.org/10.1016/j.jclep ro.2017.07.100

Jensen CD, Mcintyre S, Munday M, Turner K (2013) Responsibility for regional waste generation: a single-region extended input-output analysis for wales. Reg Stud 47:913-933. https://doi.org/10.1080/00343404.2011.599797

Kagawa S, Kudoh Y, Nansai K, Tasaki T (2008) The economic and environmental consequences of automobile lifetime extension and fuel economy improvement: Japan's case. Econ Syst Res 20:3-28. https://doi.org/10.1080/09535 310801890615

Kagawa S, Nansai K, Kudoh Y (2009) Does product lifetime extension increase our income at the expense of energy consumption? Energy Econ 31:197-210. https://doi.org/10.1016/j.eneco.2008.08.011

Kagawa S, Nakamura S, Kondo Y et al (2015) Forecasting replacement demand of durable goods and the induced secondary material flows: a case study of automobiles. J Ind Ecol 19:10-19. https://doi.org/10.1111/jiec.12184

Kirchherr J, Reike D, Hekkert M (2017) Conceptualizing the circular economy: an analysis of 114 definitions. Resour Conser Recycl. https://doi.org/10.1016/.resconrec.2017.09.005

Kondo Y, Nakamura S (2004) Evaluating alternative life-cycle strategies for electrical appliances by the waste input-output model. Int J Life Cycle Assess 9:236-246. https://doi.org/10.1007/BF02978599

Kondo Y, Nakamura S (2005) Waste input-output linear programming model with its application to eco-efficiency analysis. Econ Syst Res 17:393-408. https://doi.org/10.1080/09535310500283526

Lenzen M, Reynolds CJ (2014) A supply-use approach to waste input-output analysis. J Ind Ecol 18:212-226. https://doi. org/10.1111/jiec.12105

Lenzen M, Rueda-Cantuche JM (2012) A note on the use of supply-use tables in impact analyses. Sort 36:139-152

Lenzen M, Geschke A, Wiedmann T et al (2014) Compiling and using input-output frameworks through collaborative virtual laboratories. Sci Total Environ 485-486:241-251. https://doi.org/10.1016/j.scitotenv.2014.03.062

Li J, Lin C, Huang SA (2013) Considering variations in waste composition during waste input-output modeling. J Ind Ecol 17:892-899. https://doi.org/10.1111/jiec.12068

Liao MI, Chen PC, Ma HW, Nakamura S (2015) Identification of the driving force of waste generation using a high-resolution waste input-output table. J Clean Prod 94:294-303. https://doi.org/10.1016/j.jclepro.2015.02.002 
Lieder M, Rashid A (2016a) Towards circular economy implementation: a comprehensive review in context of manufacturing industry. J Clean Prod 115:36-51. https://doi.org/10.1016/j.jclepro.2015.12.042

Lieder M, Rashid A (2016b) Towards circular economy implementation: a comprehensive review in context of manufacturing industry. J Clean Prod 115:36-51. https://doi.org/10.1016/j.jclepro.2015.12.042

Lin C (2011) Identifying lowest-emission choices and environmental pareto frontiers for wastewater treatment wastewater treatment input-output model based linear programming. J Ind Ecol 15:367-380. https://doi.org/10.111 1/j.1530-9290.2011.00339.x

Linder M, Sarasini S, van Loon P (2017) A metric for quantifying product-level circularity. J Ind Ecol. https://doi. org/10.1111/jiec.12552

McDowall W, Geng Y, Huang B et al (2017) Circular economy policies in China and Europe. J Ind Ecol 21:651-661. https:// doi.org/10.1111/jiec.12597

McKinsey\&Company (2016) The circular economy: moving from theory to practice

Merciai S, Schmidt J (2018) Methodology for the construction of global multi-regional hybrid supply and use tables for the EXIOBASE v3 database. J Ind Ecol. https://doi.org/10.1111/jiec.12713

Miller RE, Blair PD (2009) Input-output analysis: foundations and extensions, 2nd edn. Cambridge University Press, New York

Murray A, Skene K, Haynes K (2015) The circular economy: an interdisciplinary exploration of the concept and application in a global context. J Bus Ethics 140:369-380. https://doi.org/10.1007/s10551-015-2693-2

Nakajima K, Ohno H, Kondo Y et al (2013) Simultaneous material flow analysis of nickel, chromium, and molybdenum used in alloy steel by means of input-output analysis. Environ Sci Technol 47:4653-4660. https://doi.org/10.1021/ es3043559

Nakamura S (1999a) An interindustry approach to analyzing economic and environmental effects of the recycling of waste. Ecol Econ 28:133-145. https://doi.org/10.1016/50921-8009(98)00031-7

Nakamura S (1999b) Input-output analysis of waste cycles. In: Proceedings first international symposium on environmentally conscious design and inverse manufacturing. IEEE, pp 475-480

Nakamura S, Kondo Y (2002) Input-output analysis of waste management. J Ind Ecol 6:39-63. https://doi. org/10.1162/108819802320971632

Nakamura S, Kondo Y (2006) A waste input-output life-cycle cost analysis of the recycling of end-of-life electrical home appliances. Ecol Econ 57:494-506. https://doi.org/10.1016/j.ecolecon.2005.05.002

Nakamura S, Kondo Y (2009) Waste input-output analysis: concepts and application to industrial ecology. Springer, Heidelberg

Nakamura S, Nakajima K (2005) Waste input-output material flow analysis of metals in the Japanese economy. Mater Trans 46:2550-2553. https://doi.org/10.2320/matertrans.46.2550

Nakamura S, Nakajima K, Kondo Y, Nagasaka T (2007a) The waste input-output approach to materials flow analysis—concepts and application to base metals. J Ind Ecol 11:50-63. https://doi.org/10.1162/jiec.2007.1290

Nakamura S, Nakajima K, Kondo Y, Nagasaka T (2007b) The waste input-output approach to materials flow analysis. J Ind Ecol 11:50-63. https://doi.org/10.1162/jiec.2007.1290

Nakamura S, Nakajima K, Yoshizawa Y et al (2009) Analyzing polyvinyl chloride in Japan with the waste input-output material flow analysis model. J Ind Ecol 13:706-717. https://doi.org/10.1111/j.1530-9290.2009.00153.x

Nakamura S, Kondo Y, Kagawa S et al (2014) MaTrace: tracing the fate of materials over time and across products in openloop recycling. Environ Sci Technol 48:7207-7214. https://doi.org/10.1021/es500820h

Nishijima D (2017) The role of technology, product lifetime, and energy efficiency in climate mitigation: a case study of air conditioners in Japan. Energy Pol 104:340-347. https://doi.org/10.1016/j.enpol.2017.01.045

Ohno H, Matsubae K, Nakajima K et al (2014) Unintentional flow of alloying elements in steel during recycling of end-oflife vehicles. J Ind Ecol 18:242-253. https://doi.org/10.1111/jiec.12095

Ohno H, Nuss P, Chen WQ, Graedel TE (2016) Deriving the metal and alloy networks of modern technology. Environ Sci Technol 50:4082-4090. https://doi.org/10.1021/acs.est.5b05093

Ohno H, Matsubae K, Nakajima K et al (2017) Optimal recycling of steel scrap and alloying elements: input-output based linear programming method with its application to end-of-life vehicles in Japan. Environ Sci Technol. https://doi. org/10.1021/acs.est.7b04477

Pauliuk S (2017) Critical appraisal of the circular economy standard BS 8001:2017 and a dashboard of quantitative system indicators for its implementation in organizations. Resour Conserv Recycl 129:81-92. https://doi.org/10.1016/j. resconrec.2017.10.019

Pauliuk S, Kondo Y, Nakamura S, Nakajima K (2017) Regional distribution and losses of end-of-life steel throughout multiple product life cycles_insights from the global multiregional MaTrace model. Resour Conserv Recycl 116:84-93. https://doi.org/10.1016/j.resconrec.2016.09.029

Pearce D, Turner R (1990) Economics of natural resources and the environment. Harvester Wheatsheaf, New York

Peters GP, Hertwich EG (2009) The application of multi-regional input-output analysis to industrial ecology. In: Suh S (ed) Handbook of input-output economics in industrial ecology. Springer, Dordrecht, pp 847-848

Potting J, Hekkert M, Worrell E, Hanemaaijer A (2017) Circular economy: measuring innovation in the product chain. The Hague

Pratt K, Lenaghan M (2015) The carbon impacts of the circular economy technical report

Reutter B, Lant P, Lane J et al (2017) Food waste consequences: environmentally extended input-output as a framework for analysis. J Clean Prod 153:506-514. https://doi.org/10.1016/j.jclepro.2016.09.104

Reynolds CJ, Piantadosi J, Boland J (2014) A waste supply-use analysis of australian waste flows. J Econ Struct 3:5. https:// doi.org/10.1186/s40008-014-0005-0

Reynolds CJ, Piantadosi J, Boland J (2015) Rescuing food from the organics waste stream to feed the food insecure: an economic and environmental assessment of australian food rescue operations using environmentally extended waste input-output analysis. Sustainability 7:4707-4726. https://doi.org/10.3390/su7044707 
Reynolds C, Geschke A, Piantadosi J, Boland J (2016a) Estimating industrial solid waste and municipal solid waste data at high resolution using economic accounts: an input-output approach with Australian case study. J Mater Cycles Waste Manag 18:677-686. https://doi.org/10.1007/s10163-015-0363-1

Reynolds C, Mirosa M, Clothier B (2016b) New Zealand's food waste: estimating the tonnes, value, calories and resources wasted. Agriculture 6:9. https://doi.org/10.3390/agriculture6010009

Rodrigues JFD, Lorena A, Costa I et al (2016) An input-output model of extended producer responsibility. J Ind Ecol 20:1273-1283. https://doi.org/10.1111/jiec.12401

Rutherford TF, Böhringer C (2015) The circular economy —an economic impact assessment report to SUN-IZA, pp 1-33

Salemdeeb R, Al-tabbaa A, Reynolds C (2016) The UK waste input-output table: linking waste generation to the UK economy. Waste Manag Res 34:1089-1094. https://doi.org/10.1177/0734242X16658545

Shigetomi Y, Nansai K, Kagawa S, Tohno S (2015) Trends in Japanese households' critical-metals material footprints. Ecol Econ 119:118-126. https://doi.org/10.1016/j.ecolecon.2015.08.010

Skelton ACH, Allwood JM (2013) The incentives for supply chain collaboration to improve material efficiency in the use of steel: an analysis using input output techniques. Ecol Econ 89:33-42. https://doi.org/10.1016/j.ecole con.2013.01.021

Takase K, Kondo Y, Washizu A (2005) An analysis of sustainable consumption by the waste input-output model. J Ind Ecol 9:201-219. https://doi.org/10.1162/1088198054084653

Takeyama K, Ohno H, Matsubae K et al (2016) Dynamic material flow analysis of nickel and chromium associated with steel materials by using matrace. Matériaux Tech 104:610. https://doi.org/10.1051/mattech/2017012

Tisserant A, Pauliuk S, Merciai S et al (2017) Solid waste and the circular economy: a global analysis of waste treatment and waste footprints. J Ind Ecol. https://doi.org/10.1111/jiec.12562

Tsukui M, Kagawa Shigemi, Kondo Y (2011) Urban growth and waste management optimization towards "zero waste city". Cult Soc 2:177-187. https://doi.org/10.1016/j.ccs.2011.11.007

Tsukui M, Ichikawa T, Kagatsume M (2017) Repercussion effects of consumption by domestic tourists in Tokyo and Kyoto estimated using a regional waste input-output approach. J Econ Struct. https://doi.org/10.1186/s4000 8-017-0061-3

Tukker A, Dietzenbacher E (2013) Global multiregional input-output frameworks: an introduction and outlook global multiregional input-output. Econ Syst Res 25:1-19. https://doi.org/10.1080/09535314.2012.761179

Tukker A, de Koning A, Wood R et al (2013) Exiopol_-development and illustrative analyses of a detailed global Mr Ee Sut/lot. Econ Syst Res 25:50-70. https://doi.org/10.1080/09535314.2012.761952

Tukker A, Bulavskaya T, Giljum S et al (2016) Environmental and resource footprints in a global context: Europe's structural deficit in resource endowments. Glob Environ Chang 40:171-181. https://doi.org/10.1016/j.gloenvcha.2016.07.002

WEF (2014) Towards the Circular Economy: Accelerating the scale-up across global supply chains

Weisz H, Duchin F (2006) Physical and monetary input-output analysis: what makes the difference? Ecol Econ 57:534541. https://doi.org/10.1016/j.ecolecon.2005.05.011

Wiedmann T (2009) A review of recent multi-region input-output models used for consumption-based emission and resource accounting. Ecol Econ 69:211-222. https://doi.org/10.1016/j.ecolecon.2009.08.026

Wiedmann TO, Schandl H, Lenzen M et al (2015) The material footprint of nations. PNAS 112:6271-6276. https://doi. org/10.1073/pnas.1220362110

Winans K, Kendall A, Deng H (2017) The history and current applications of the circular economy concept. Renew Sustain Energy Rev 68:825-833. https://doi.org/10.1016/j.rser.2016.09.123

Winning M, Calzadilla A, Bleischwitz R, Nechifor V (2017) Towards a circular economy: insights based on the development of the global ENGAGE-materials model and evidence for the iron and steel industry. Int Econ Econ Policy. https:// doi.org/10.1007/s10368-017-0385-3

Wohlin C (2014) Guidelines for snowballing in systematic literature studies and a replication in software engineering. In: Proceedings 18th international conference evaluation assessment in software engineering (EASE'14), pp 1-10. https://doi.org/10.1145/2601248.2601268

Wood R, Stadler K, Bulavskaya T et al (2015) Global sustainability accounting-developing EXIOBASE for multi-regional footprint analysis. Sustainability 7:138-163. https://doi.org/10.3390/su7010138

Yokoyama K, Onda T, Kashiwakura S, Nagasaka T (2006) Waste input-output analysis on landfill mining activity. Mater Trans 47:2582-2587. https://doi.org/10.2320/matertrans.47.2582

Zink T, Geyer R (2017) Circular economy rebound. J Ind Ecol. https://doi.org/10.1111/jiec.12545 (In press) 